\title{
Correction to: Industrial Policy: Some Case Studies from Today's World
}

\section{Correction to:}

Chapter 13 in: M. A. Yülek, How Nations Succeed, https://doi.org/10.1007/978-981-13-0568-9_13

In Table 13.1, shaded areas have been included to the timeline of the events indicated in the leftmost column.

The updated online version of this chapter can be found at https://doi.org/10.1007/978-981-13-0568-9_13 